\title{
MONTEIRO LOBATO NO BANCO DOS RÉUS: O TEMA DA JUDICIALIZAÇÃO DAS CAÇADAS DE PEDRINHO
}

\section{Arnaldo Sampaio de Moraes Godoy ${ }^{1}$}

\begin{abstract}
RESUMO: O ensaio problematiza importante questão historiográfica a propósito dos julgamentos que fazemos para com pessoas e fatos do passado. Comenta-se discussão judicial em torno de excertos do escritor Monteiro Lobato, reputadamente progressista, a quem se acusou, no entanto, de explicitar ideias racistas.
\end{abstract}

Palavras-Chave: Monteiro Lobato; historiografia; acusações de racismo; Supremo Tribunal Federal.

\section{INTRODUÇÃO}

Há um recorrente problema historiográfico que identifica armadilhas em que incorremos quando julgamos pessoas e seus atos em contextos distintos dos quais essas pessoas viveram e esses atos foram praticados. Protagoniza-se "um salto do tigre em relação ao passado" (Benjamin, 1985, p. 261), selecionando-se instâncias e ocorrências, desafiando-se uma realidade ocorrida, desprezando-se que toda realidade é histórica e que todo conhecimento seja um conhecimento histórico (cf. Collingwood, 2001, p. 171). Experiências humanas perdem a contextualização, reduzem-se a fragmentos, anulando suas identidades, em processo de desintegração caótico e irradiador, a exemplo do que ocorre com as próprias coisas e objetos (Matos, 1993, p. 13).

E porque inconscientemente consideramos o passado como um modelo para o presente (Le Goff, 1988, p. 43), com alguma injustiça, colocamos em cena personagens e mentalidades, como se fossem peças de

\footnotetext{
1 Livre-docente em Teoria Geral do Estado pela Faculdade de Direito da Universidade de São Paulo (USP). Pós-doutor em Direito Comparado pela Boston University e em Teoria Literária pela Universidade de Brasília (UnB). Doutor e Mestre em Filosofia do Direito e do Estado pela Pontifícia Universidade católica de São Paulo (PUC-SP). Brasília, DF, Brasil. $\quad$ CV Lattes: $\quad$ http://lattes.cnpq.br/2987368350054932. $\quad$ E-mail: <
} 
uma mosaico opaco e indefinido, identificadores de uma "galeria da história" (De Certeau, 2007, p. 106). Uma representação histórica talvez contenha menos do que se representa, em favor daquele que constrói a representação, qualificando-se a natureza lacunar do esforço de compreensão do passado (Veyne, 1998, p. 26). Há um juízo moral na história (cf. Croce, 1962, p. 169 e ss.), e desse juízo moral não se consegue escapar.

É nesse contexto substancialmente perturbador que se pretende inserir debate levado ao judiciário, a respeito de fragmento da obra do escritor José Bento Monteiro Lobato, quando se imputou, ainda que indiretamente, conteúdo racista em excertos de uma literatura produzida para o público infantil, destinatário de uma obra que transcendeu no tempo e que hoje ainda é apreciada, pelo que são inegáveis os efeitos que suscita. É do que se trata no presente ensaio, que principia com uma síntese da irreverência generalizada que marcou a obra de Monteiro Lobato, especialmente em relação aos arranjos institucionais de seu tempo. Em seguida, pretende-se uma resenha dos fatos debatidos no Supremo Tribunal Federal, alavancando-se um conjunto de conclusões que aponta para as aporias de nosso tempo.

\section{MONTEIRO LOBATO EM SEU CONTEXTO LITERÁRIO, POLÍTICO E EXPERIMENTAL}

Monteiro Lobato nasceu em Taubaté, São Paulo, em 18 de abril de 1882. Registrado como José Renato Monteiro Lobato, mais tarde mudou o nome para José Bento Monteiro Lobato, ao que consta para valer-se das iniciais JBML e usar uma bengala deixada pelo pai, cujo nome era José Bento. Pressionado pelo avô, o Visconde de Tremembé, seguiu para São Paulo onde bacharelou-se.

O desinteresse de Monteiro Lobato pelo curso de Direito era total. Parece que apreciava apenas um professor, Pedro Lessa, que lecionava Filosofia do Direito (Cavalheiro, [s.d.], p. 5). Durante os anos de faculdade, Monteiro Lobato aprofundou amizades com as quais o interesse comum era a Literatura. Concluído o curso de Direito, retornou a Taubaté; foi festivamente recebido como Bacharel. Nomeado promotor, mudou-se para Areias, no interior paulista. Casou-se em 1908 e no ano seguinte herdou a fazenda do avô. Deixou o Ministério Público e tornou-se fazendeiro. 
Em meados da década de 1910, começou a publicar contos, crônicas, um pouco de crítica. Após vender a fazenda, mudou-se para São Paulo, fundou uma editora em 1918. Faliu sete anos depois e transferiu-se para o Rio de Janeiro. Na então capital da República, colaborou na imprensa com certo destaque. Em 1926, seguiu para Nova Iorque e lá morou até 1931. Foi adido comercial brasileiro. Impressionado com o crescimento econômico dos Estados Unidos, dedicou-se a fazer proselitismo em torno da exploração do petróleo e do ferro. Em virtude de intransigente luta em prol de soberania nos direitos de exploração do subsolo, foi preso, em 1941, por três meses. Seguiu para a Argentina em 1946, lá vivendo um ano. Ao retornar ao Brasil, era pranteado e festejado autor de livros infantis. Morreu em 4 de julho de 1948, em virtude de um espasmo vascular.

O curso jurídico foi uma imposição do avô, de quem herdou a fazenda. Depois de rápida passagem por Taubaté, terra do avô, foi designado promotor em Areias. À época, virada do século, o Ministério Público não tinha o perfil que tem na contemporaneidade. Não gostava do júri. Detestava acusar os pobres réus. Afastava-se do tabelião. Não tinha vínculo ideológico com o Juiz. Não lia autores de Direito. Jamais escreveu artigo jurídico. Lobato deixou Areias e a vida de promotor, para a qual não se sentia talhado (Cavalheiro, [s.d.]).

Carregado de desilusão, de pessimismo, e de ceticismo, Lobato lutou pela superação desse vazio, o que suscitou uma literatura crítica. É o caso do sublime conto Júri na roça, e de tantas outras peças literárias absolutamente irônicas e mordazes. Por exemplo, Lobato foi um crítico agudo do modelo tributário. Em Ideias de Jeca Tatu, ao descrever a chegada da família real portuguesa no Brasil, Lobato chama a atenção para o desembarque de um personagem: "O Fisco - um canzarrão tremendo de dentuça arreganhada - é conduzido no açamo por vários meirinhos" (Lobato, 1950, p. 14).

A guerra que Lobato fazia ao fisco (e que de certo modo teve alguns resultados, dada a imunidade tributária dos livros, que tanto defendeu) é mais uma faceta de seu espírito combativo. Lobato também acreditava que a vida do operador jurídico é vazia porque as condições determinantes da 
justiça são estruturais, dependentes da justiça econômica, fundamentada na boa distribuição de renda.

Criticava abertamente as concepções formais de Direito e de Justiça, no sentido de que

Se o Direito representasse um reverbero da Justiça como a sonham filósofos, o direito endurar-se-ia na consciência de cada homem, confundindo-se com a moral e dispensando a sanção. Por que existem hoje, como outrora, como sempre, tantos infratores das leis? Porque tais leis só representam conservação, permanência, status quo de fato, e nunca uma pura emanação da justiça (Lobato, 195ob, p. 17-18).

Lobato detinha um aguçadíssimo espírito crítico que não contemporizava com as iniquidades que vira, inclusive como promotor. Seu ceticismo radical matizou uma incredulidade mórbida e perene para com concepções formais dos campos jurídicos. Sua efetividade prática, seu espírito empreendedor e sua mobilidade fática repeliam o abstrato, o teórico, o conceitual, que desenham o Direito, como criação eminentemente cultural. Seu inconformismo constante o afastou das soluções impostas.

Monteiro Lobato viveu num contexto muito diferente do nosso contexto atual. Seu primeiro livro para crianças, Reinações de Narizinho, foi lançado em 1920, ano marcado pelo antagonismo entre os tenentes rebeldes e o Presidente Epitácio Pessoa, ponto de partida para uma década absolutamente difícil, e que se desdobrou no movimento conduzido a partir do Rio Grande do Sul por Getúlio Vargas. Lobato combateu Vargas, especialmente por causa da resistência deste último em reconhecer a existência do petróleo brasileiro, posição que alterou substancialmente na década de 1950.

A obra infantil de Monteiro Lobato também alcançou um grande número de adaptações, que fizeram muito sucesso, a exemplo de Dom Quixote das crianças, Os doze trabalhos de Hércules, Fábulas, Aventuras de Hans Staden, Peter Pan, História do mundo para as crianças, O Minotauro. Também criou um universo infantil absolutamente contagiante para muitas gerações, a exemplo das estórias que lemos em Viagem ao céu, O Saci, O Picapau Amarelo, A reforma da natureza, A chave do tamanho, A reforma da natureza, Memórias da Emília, Caçadas de Pedrinho. 
Este último, Caçadas de Pedrinho, cujo conteúdo também foi questionado em juízo, originou-se de um livro escrito por Monteiro Lobato ainda em 1924, A Caçada da onça. A versão final é de 1933. Nesse livro os personagens mirins perseguem onças-pintadas, porcos do mato, rinocerontes. Acusarmos Monteiro Lobato por incitação ao crime ambiental é incriminação que desconsidera o delito historiográfico de julgarmos as pessoas fora dos contextos e ambientes nos quais viveram. No entanto, porque há também gravíssimas imprecações de fundo racista, a questão pode suscitar outra abordagem, justamente como se vê em seguida, ainda que resumidamente.

\section{A JUDICIALIZAÇÃO DA OBRA DE MONTEIRO LOBATO}

O Instituto de Advocacia Racial (IARA) é um dos impetrantes de mandado de segurança no Supremo Tribunal Federal (STF) em face da Presidente da República, do Ministro da Educação (MEC), do Presidente do Conselho Nacional de Educação (CNE), bem como da então relatora de processo na Câmara de Educação Básica do Conselho Nacional de Educação. O mandado de segurança foi relatado pelo Ministro Luiz Fux, que indeferiu a pretensão dos interessados, ainda que por razões de forma (incompetência do STF) e não de conteúdo.

Requeria-se liminar para que se desse efeito suspensivo à homologação ministerial de Parecer do MEC, até que tivesse decisão de pedido de avocação extraordinária de recurso, interposto junto à Presidência da República. Um parecer do Conselho Nacional de Educação (no 6-2011), homologado pelo Ministro da Educação, retirou validade de parecer anterior ( $n^{0}$ 15-2010), tratando diferentemente a questão do controle de obras com eventual manifestação racista. Essa mudança de tratamento, que impediria o monitoramento de obras que pudessem eventualmente explicitar conteúdo racista, é o núcleo procedimental da questão aqui trazida.

Para os impetrantes, o pedido de revisão do Parecer $n^{0} 15-2010$ fora feito pelo Chefe de Gabinete do Ministro da Educação, e não pelo próprio Ministro, que deteria competência exclusiva na matéria; por isso, a revisão seria nula. Pretendiam que a Presidente avocasse o mencionado processo administrativo, e até decisão final, esperavam suspensão da orientação do 
Parecer $n^{0}$ 6-2011. O Parecer $n^{0}$ 15-2010 tratava de modo mais enfático uma política definidora de controle e combate à divulgação de livros que contivessem conteúdos explicitamente racistas.

Objetivamente, pretendia-se modelo de capacitação de educadores para uso de livro com conteúdo racista. Haveria necessidade de consignação de nota explicativa de apresentação obrigatória, dado que no livro criticado havia nota explicativa de uso de nova ortografia e de proteção do IBAMA em relação aos animais. Não havia por parte dos impetrantes, bem entendido, requerimento para banimento da obra ou qualquer forma de censura mais contundente.

Os impetrantes pretendiam que se publicasse uma nota explicativa e de esclarecimentos ao leitor da obra questionada. Invocavam que o livro suscitava temas da criminalização do racismo, e que um direito potestativo à educação determinava que se valorizasse a cultura africana. Cuida-se de um direito público subjetivo a uma educação antirracista. Invocou-se que a obra questionada poderia redundar em violação da igualdade racial.

No mérito, demonstrou-se o uso, por parte de Monteiro Lobato, de expressões de estereótipos raciais quando de referências e falas da personagem Tia Anastácia, no livro Caçadas de Pedrinho. Para os impetrantes, o Ministério da Educação infringiu as normas gerais da Administração Pública e a legislação sobre o racismo ao autorizar a aquisição de livros que contenham expressões reforçadoras de estereótipos raciais. De fato, em uma das edições hoje comercializadas, lê-se, na conclusão do livro, Tia Anastácia afirmando "Negro também é gente, Sinhá...” (Lobato, 2011, p. 71). Essa passagem, entre outras, é a razão da insurgência, que ocasionou a judicialização do assunto.

$\mathrm{Na}$ origem da discussão, do ponto de vista burocrático, está a notícia de um requerimento com pedido de avocação extraordinária, por parte de um dos impetrantes, como cidadão, junto ao MEC, com o objetivo de providências na divulgação da obra aqui comentada. O livro seria distribuído no contexto de um programa nacional de fomento a bibliotecas públicas (Programa Nacional Biblioteca na Escola-PNBE). Observou-se que teria havido demora da presidência em avocar processo administrativo em que se discute decisão do Ministério da Educação, que modificou parecer do Conselho Nacional da Educação. 
A impetrada, Presidente da República, prestou informações consignando que não haveria fumaça do bom direito e o perigo na demora da prestação jurisdicional, para efeitos de concessão da liminar; isto é, não haveria um ato concreto a ser corrigido. $O$ interessado deveria peticionar no Ministério de Educação e aguardar manifestação daquela Pasta.

Explicou-se que o Conselho Nacional de Educação havido emitido parecer ( $n^{0}$ 15-2010) suscitando que se fizesse constar das obras que presumivelmente contivessem cunho racista uma nota explicativa, de forma a contextualizar a obra literária. O MEC produziu nota técnica contrariando o Conselho, solicitando revisão do parecer, invocando a inadequação pedagógica de se inserir esse tipo de nota em texto literário, reiterando a importância da obra para a formação cultural dos alunos. Afinal, um colegiado formado por especialistas em Literatura e Educação e por técnicos das secretarias estaduais e municipais de todo o país escolhera o livro questionado. Observou-se que a obra literária deveria levar em conta seu registro histórico, sem o qual ficaria descontextualizada. Ponderou-se que inserção de nota explicativa limitaria a leitura da obra, retirando dos leitores a autonomia e a oportunidade para reflexão crítica.

O Conselho Nacional de Educação (Parecer $n^{0}$ 6-2011) insistiu que o direito de liberdade de expressão é característico de uma sociedade democrática, pelo que não se poderia vetar circulação de obra literária e artística. Porém, temperou-se essa linha, consignando-se que também se deva garantir o direito à não discriminação, por força mesmo de determinações constitucionais, legais e convencionais. Reconheceu-se ao mesmo tempo a qualidade ficcional da obra de Monteiro Lobato. E lembrou-se nossa sujeição a nossas próprias épocas, bem como nossa responsabilidade para com opções e orientações políticas, pedagógicas e literárias que assumimos nos contextos nos quais vivemos. E a literatura, colhe-se no mencionado parecer, por estar em sintonia com mundo, "não está fora dos conflitos, das hierarquias de poder e das tensões sociais e raciais nas quais o trato à realidade se realiza”.

O Ministro do STF que relatou o processo conduziu e mediou audiência de conciliação, ocasião em que se interpretou que os pareceres mencionados se adensavam mutuamente, razão pela qual não havia necessidade de correção. No mérito, decidiu-se que não se demonstrou 
ilegalidade ou abuso de poder. Fixou-se também a incompetência do STF para se pronunciar sobre a matéria, por conta de que não se vislumbrou necessidade de avocação dos autos pela chefia do Executivo Federal, única circunstância justificativa de reconhecimento da competência do STF para decidir a questão.

\section{CONCLUSÕES}

Essa discussão coloca-nos, entre tantos outros problemas, uma questão historiográfica de difícil resolução. Não se pode isolar Monteiro Lobato do contexto no qual viveu, ambiente prenhe de uma herança histórica, maldita, e que percebia a herança escravocrata dentro de uma naturalidade que hoje não conseguimos compreender. Colocá-lo no banco dos réus, nesse sentido, é atitude presunçosa de nosso tempo, que detém algum benefício de retrospecto. Não se faria justiça à imensa colaboração crítica desse grande escritor, no contexto de nossa história literária.

Por outro lado, há um elemento perverso de recepção de textos, por intermédio do qual não nos libertamos de nosso tempo e de nossas instâncias e categorias de pensamento. Não se pode dissimular que há um conteúdo ofensivo em alguns fragmentos da obra questionada, e que se deve mitigar a dor e a humilhação dos atingidos, porque efetivamente existentes.

A solução média, que não contempla o banimento ou a censura pura e simples da obra, consistiria na construção de mecanismos de esclarecimento, matizados pela formação de professores que mediarão as leituras propostas, instrumentalizadas também por notas explicativas circunstanciais, com os naturais custos de aquiescência para com uma política humanista e de esclarecimento.

\section{REFERÊNCIAS}

BENJAMIN, Walter. Essays and Reflections. Trad. de Harry Zohn. New York: Schocken Books, 1985.

COLLINGWOOD, R. G. The Principles of History and other writings in Philosophy of History. Oxford: Oxford University Press, 2001.

CROCE, Benedetto. A história: pensamento e ação. Trad. de Darcy Damasceno. Rio de Janeiro: Zahar, 1962.

DE CERTEAU, Michel. A escrita da história. Trad. de Maria de Lourdes Menezes. Rio de Janeiro: Forense Universitária, 2007. 
LE GOFF, Jacques. Histoire et Mémoire. Paris: Gallimard, 1988.

LOBATO, José Bento Monteiro. Ideias de Jeca Tatu. São Paulo: Brasiliense, 1950.

LOBATO, José Bento Monteiro. Mundo da lua e miscelânea. São Paulo: Brasiliense, $1950 \mathrm{ob}$.

LOBATO, José Bento Monteiro. Caçadas de Pedrinho. São Paulo: Globo, 2011.

MATOS, Olga C. F. O iluminismo visionário: Benjamin, leitor de Descartes e Kant. São Paulo: Brasiliense, 1999.

VEYNE, Paul. Como se escreve a história. Trad. de Alda Baltar e Maria Auxiliadora Kneipp. Brasília: UnB, 1998.

Idioma original: Português

Recebido: 01/04/16

Aceito: 13/o6/16 


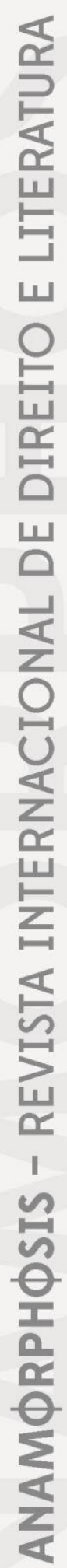

